\title{
Paris Saponins enhance radiosensitivity in a gefitinib-resistant lung adenocarcinoma cell line by inducing apoptosis and $G_{2} / M$ cell cycle phase arrest
}

\author{
PENG-JUN ZHAO ${ }^{1 *}$, SHUI-CHUAN SONG ${ }^{2 *}$, LEI-WEN DU ${ }^{2 *}$, GUO-HUA ZHOU ${ }^{3}$, \\ SHENG-LIN MA ${ }^{4}$, JIN-HUI LI ${ }^{5}$, JIAN-GUO FENG ${ }^{6}$, XIN-HAI ZHU ${ }^{7}$ and HAO JIANG ${ }^{8}$ \\ ${ }^{1}$ Department of Radiation Oncology, Hangzhou Cancer Hospital, Hangzhou, Zhejiang 310002; \\ ${ }^{2}$ Department of Gastroenterology, 117 Hospital of People's Liberation Army, Hangzhou, Zhejiang 310013; \\ ${ }^{3}$ Department of Oncology, Anji People's Hospital, Anji, Zhejiang 313399; ${ }^{4}$ Department of Oncology, \\ Hangzhou First People's Hospital, Hangzhou, Zhejiang 310006; ${ }^{5}$ Department of Chinese Medicine and Rehabilitation, \\ The Second Affiliated Hospital of Zhejiang University School of Medicine, Hangzhou, Zhejiang 310009; \\ ${ }^{6}$ Department of Oncology, Zhejiang Cancer Hospital, Hangzhou, Zhejiang 310022; \\ Departments of ${ }^{7}$ Thoracic Surgery and ${ }^{8}$ Oncology, Zhejiang Hospital, Hangzhou, Zhejiang 310013, P.R. China
}

Received April 9, 2015; Accepted December 21, 2015

DOI: $10.3892 / \mathrm{mmr} .2016 .4865$

\begin{abstract}
Acquired resistance to epidermal growth factor inhibitors has been reported to be associated with cross-resistance to radiation. Paris Saponins (PSs) exert a wide range of pharmacological activities, including cell apoptosis induction, multidrug resistance inhibition, angiogenesis inhibition and tumor cell migration by modulating various signaling pathways. The present study aimed to investigate the radiosensitization effects of PSII, PSVI and PSVII in a gefitinib-resistant PC-9-ZD lung adenocarcinoma cell line, and the possible mechanism underlying their function. A clonogenic assay was performed to determine the effects of PS radiosensitization on the PC-9-ZD cell line. The cell cycle was analyzed by flow cytometry, and cell apoptosis was analyzed with Annexin V/propidium iodide and Hoechst staining. Protein expression levels were detected by western blotting. The results of the present study revealed a significant increase in PC-9-ZD cell line radiosensitivity following treatment with PSs. PSs induced $\mathrm{G}_{2} / \mathrm{M}$ cell cycle phase arrest and apoptosis of the irradiated PC-9-ZD cells. Notably, the expression levels of B cell lymphoma 2 (Bcl-2) were downregulated, and those of caspase-3, $\mathrm{Bcl}-2$-associated $\mathrm{X}$ protein
\end{abstract}

Correspondence to: Dr Hao Jiang, Department of Oncology, Zhejiang Hospital, 12 Lingyin Road, Hangzhou, Zhejiang 310013, P.R. China

E-mail: zjyyzlk@163.com

*Contributed equally

Key words: radiosensitivity, Paris Saponin, gefitinib resistance, apoptosis
(Bax) and p21/Waf1/Cip1 were upregulated following treatment with PSs. The present results demonstrated that PSs induced radiosensitivity in gefitinib-resistant cells by inducing $\mathrm{G}_{2} / \mathrm{M}$ phase arrest and by enhancing the apoptotic response via the modulation of caspase-3, Bax, Bcl-2 and p21/Waf1/Cip1 expression.

\section{Introduction}

Lung cancer is regarded as one of the leading causes of cancer-associated mortality worldwide (1). Non-small cell lung cancer (NSCLC) accounts for $80 \%$ of lung cancers $(2,3)$. Epidermal growth factor (EGFR) is an important therapeutic target in NSCLC (4). Selective EGFR tyrosine kinase inhibitors (TKIs) such as gefitinib have been developed, and are highly effective for the treatment of EGFR-mutated NSCLC (5). Notably, the efficacy duration of these drugs is short, and patients who initially respond to TKIs inevitably relapse, suggesting that resistance may easily emerge (6-8). Gefitinib has shown measurable efficacy at early stages of treatment, but disease progression usually occurs following 6-8 months of therapy, which eventually leads to treatment failure (9). Radiation is one of the most effective therapeutic strategies for patients with NSCLC who are not eligible for a surgical procedure following chemotherapy failure (10). Although chemotherapies inhibit cancer cell growth when combined with appropriate radiotherapy, this type of treatment leads to severe side effects, including irradiation pneumonitis and suppression of the hemopoietic system $(11,12)$. Therefore, increasing tumor response to irradiation with targeted sensitizers has become the focus of numerous studies in patients with NSCLC that relapse following treatment with TKIs (13). Natural products are suitable alternatives that may be used in the treatment of cancer. In past decades, an increasing number of investigations have focused on finding anti-tumor agents from natural resources (13-35). 
In recent years, steroidal saponins have attracted scientific attention for their structural diversity and significant anti-tumor bioactivities (14-18). Steroidal saponins belong to a family of glycosides with a chemical structure that contains either a steroid or a triterpenoid attached via $\mathrm{C} 3$ and an ether bond to a sugar side chain (14-18). In addition, numerous studies have been designed to evaluate the anti-tumor effects of Paris Saponins (PSs), which are derived from the roots and rhizome of Paris polyphylla (19-25). PSI is a potent anti-tumor agent that inhibits cell proliferation and acts as a radiosensitizer for gefitinib-resistant NSCLC cells $(13,26)$. Although PSI has been extensively studied for its ability to inhibit tumor growth in various types of cancer (13,26-29), PSII, PSVI and PSVII have only recently emerged as potential anti-tumor agents (30-35). To the best of our knowledge, the radiosensitization potential of PSII, PSVI, and PSVII in TKI-resistant NSCLC has yet to be investigated. Therefore, the present study aimed to investigate the radiosensitization effects of PSII, PSVI, and PSVII in NSCLC with acquired in vitro gefitinib resistance, and also the potential mechanisms underlying their function.

\section{Materials and methods}

Drugs and reagents. PSII, PSVI and PSVII were obtained from the Zhejiang Institute for Food and Drug Control (Hangzhou, China; batches no. 111591, 111592, and 111593, respectively; $>99 \%$ purity). PSII, PSVI and PSVII (100 $\mu \mathrm{g})$ were each dissolved in $100 \mu \mathrm{l}$ dimethyl sulfoxide (DMSO) as a $100 \mu \mathrm{g} / \mu \mathrm{l}$ stock solution and stored at $-20^{\circ} \mathrm{C}$. PSII, PSVI and PSVII were then diluted in Dulbecco's modified Eagle's medium (DMEM) to achieve the final concentration of $0.5 \mu \mathrm{g} / \mathrm{ml}$ for each experiment, with a final DMSO concentration of $0.25 \%(\mathrm{v} / \mathrm{v})$. DMEM and $10 \%$ fetal bovine serum were purchased from GE Healthcare Life Sciences (Logan, UT, USA). A Cycletest ${ }^{\mathrm{TM}}$ Plus DNA Reagent kit and fluorescein isothiocyanate-Annexin V Apoptosis Detection kit were purchased from BD Biosciences (Franklin Lakes, NJ, USA). Rabbit anti-rat B cell lymphoma 2 (Bcl-2; cat. no. 3498), Bcl-2-associated X protein (Bax; cat. no. 5023), caspase-3 (cat. no. 9665) and p21/Waf1/Cip1 (cat. no. 2947) monoclonal primary antibodies at 1:1,000 dilution were purchased from Cell Signaling Technology, Inc., (Danvers, MA, USA), and mouse anti-rat glyceraldehyde 3-phosphate dehydrogenase (GAPDH) monoclonal antibody (sc-365062) from Santa Cruz Biotechnology, Inc. (Dallas, TX, USA). The horseradish peroxidase (HRP)-conjugated goat anti-rabbit IgG (heavy \& light chain) polyclonal antibody (611-1302) was purchased from Rockland, Inc. (Limerick, PA, USA).

Cell culture. A PC-9-ZD NSCLC cell line (36) resistant to gefitinib following long-term exposure to the drug was obtained from the Laboratory of Biochemistry and Molecular Biology, Tongji University (Shanghai, China). The PC-9-ZD cells were cultured to $80 \%$ confluence in DMEM supplemented with $10 \% \mathrm{FBS}, 100 \mu \mathrm{g} / \mathrm{ml}$ penicillin and $100 \mu \mathrm{g} / \mathrm{ml}$ streptomycin (both Sigma-Aldrich, St. Louis, MO, USA) for 2 weeks at $37^{\circ} \mathrm{C}$ in a humidified atmosphere containing $5 \% \mathrm{CO}_{2}$.

Clonogenic assay. The PC-9-ZD cells were divided into four experimental groups, as follows: i) The control group; ii) the PS group; iii) the radiation group; and iv) the PS + radiation group. The control group received no treatment, whereas the PS group was subdivided into three groups that were treated with $0.5 \mu \mathrm{g} / \mathrm{ml}$ PSII, PSVI or PSVII for $3 \mathrm{~h}$. The radiation group was irradiated at 4 Gy with a 6-MV X-ray, and the PS + radiation group was treated with PSII, PSVI or PSVII for $3 \mathrm{~h}$, then irradiated at $4 \mathrm{~Gy}$ with a 6-MV X-ray. After $24 \mathrm{~h}$, the cells were trypsinized (Thermo Fisher Scientific, Inc., Waltham, MA, USA) and then counted under the Olympus CKX41 inverted light microscope (Olympus Corporation, Tokyo, Japan). Subsequently, the cells were seeded at 1,000 cells/flask and cultured for 14 days at $37^{\circ} \mathrm{C}$ in a humidified atmosphere containing $5 \% \mathrm{CO}_{2}$. The colonies were then fixed using a mixture of methanol and glacial acetic acid (3:1; Sigma-Aldrich), stained with crystal violet (Sigma-Aldrich), and counted under the Olympus CKX41 inverted light microscope. Only colonies containing $>50$ cells were scored. The experiments were performed in triplicate.

Apoptosis assay. Apoptosis levels were measured using a fluorescein isothiocyanate-Annexin V Apoptosis Detection kit (eBioscience, Inc., San Diego, CA, USA). The cells in all groups were harvested at $24 \mathrm{~h}$ following treatments (or no treatments for the control) and stained with $5 \mu \mathrm{l} \mathrm{PI}(2.5 \mu \mathrm{g} / \mathrm{ml})$ and $5 \mu \mathrm{l}$ Annexin V. Apoptosis levels were detected by flow cytometry (Beckman Coulter, Inc., Brea, CA, USA).

Cell cycle assay. The radiation group received 4 Gy irradiation treatment and the PS + radiation group received 4 Gy irradiation followed by treatment with PSII, PSVI and PSVII. The cells were harvested at 12,24 and $48 \mathrm{~h}$ prior to being fixed with $70 \%$ ethanol and stored overnight at $-20^{\circ} \mathrm{C}$. The cells were then centrifuged at $300 \mathrm{x} \mathrm{g}$ for $5 \mathrm{~min}$ at $20^{\circ} \mathrm{C}$, and washed twice with phosphate-buffered saline. The cells were labeled with PI $(50 \mathrm{mg} / \mathrm{ml})$ and protected from the light for $30 \mathrm{~min}$ prior to analysis by flow cytometry and a Kaluza software, version 1.20 (Beckman Coulter, Inc.). The experiments were performed in triplicate.

Western blot analysis. The cells were treated with PSII, PSVI and PSVII for $3 \mathrm{~h}$ prior to being irradiated at a dose of $4 \mathrm{~Gy}$ and incubated for $24 \mathrm{~h}$. The cells were lysed with lysis buffer containing $50 \mathrm{mM}$ Tris- $\mathrm{HCl}(\mathrm{pH} 8.0)$ and $150 \mathrm{mM}$ $1 \%$ Triton X-100 (Sigma-Aldrich). The concentration of protein in the cell lysate was determined using the Bradford Protein Assay (Bio-Rad Laboratories, Inc., Hercules, CA, USA). Equal amounts of protein $(100 \mu \mathrm{g})$ were separated by $10 \%$ sodium dodecyl sulfate-polyacrylamide gel electrophoresis and transferred to nitrocellulose membranes (Thermo Fisher Scientific). The membranes were blocked using bovine serum albumin (GE Healthcare Life Sciences) to prevent non-specific binding, prior to incubation overnight at $4^{\circ} \mathrm{C}$ with rabbit anti-rat Bcl-2, Bax, caspase-3 and p21/Waf1/Cip1 monoclonal antibodies and mouse anti-rat GAPDH monoclonal antibody (all 1:1,000). Subsequently, the membranes were washed three times with Tris-buffered saline supplemented with Tween-20 (Sigma-Aldrich), prior to incubation for $2 \mathrm{~h}$ at room temperature with the HRP-conjugated goat anti-rabbit $\operatorname{IgG}$ secondary antibody (1:10,000). The membranes were visualized using an enhanced chemiluminescence system (Immun-Star ${ }^{\mathrm{TM}} \mathrm{AP}$ Chemiluminescence kit; Bio-Rad Laboratories, Inc.) and X-ray films (Santa Cruz 

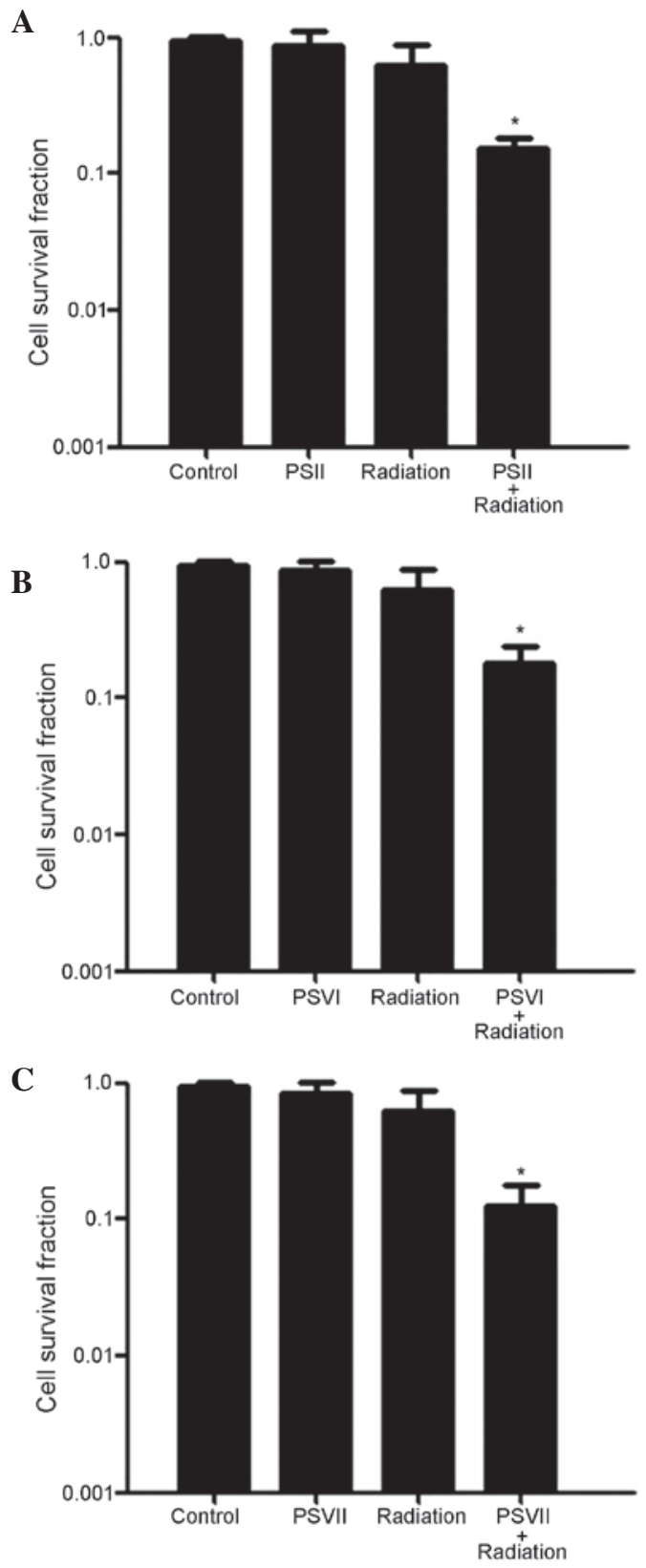

Figure 1. Clonogenic survival of gefitinib-resistant PC-9-ZD lung adenocarcinoma cells. The cells were exposed to radiation (4 Gy) and (A) PSII, (B) PSVI or (C) PSVII $(0.5 \mu \mathrm{g} / \mathrm{ml}$ each). Following cell incubation for 14 days, the number of colonies with $>50$ cells were scored. Data are presented as the mean \pm standard deviation. ${ }^{*} \mathrm{P}<0.01$ vs. the radiation group. PS Paris Saponins.

Biotechnology Inc.). The blots were analyzed using Quantity One software, version 4.6 (Bio-Rad Laboratories).

Statistical analysis. The results of the present study were compared by one-way analysis of variance using SPSS software, version 17.0 (SPSS, Inc., Chicago, IL, USA). The experimental data are presented as the mean \pm standard deviation. $\mathrm{P}<0.05$ was considered to indicate a statistically significant difference.

\section{Results}

PSII, PSVI and PSVII enhance the radiosensitivity of PC-9-ZD cells. To investigate the effects of PS on radiosensitivity in
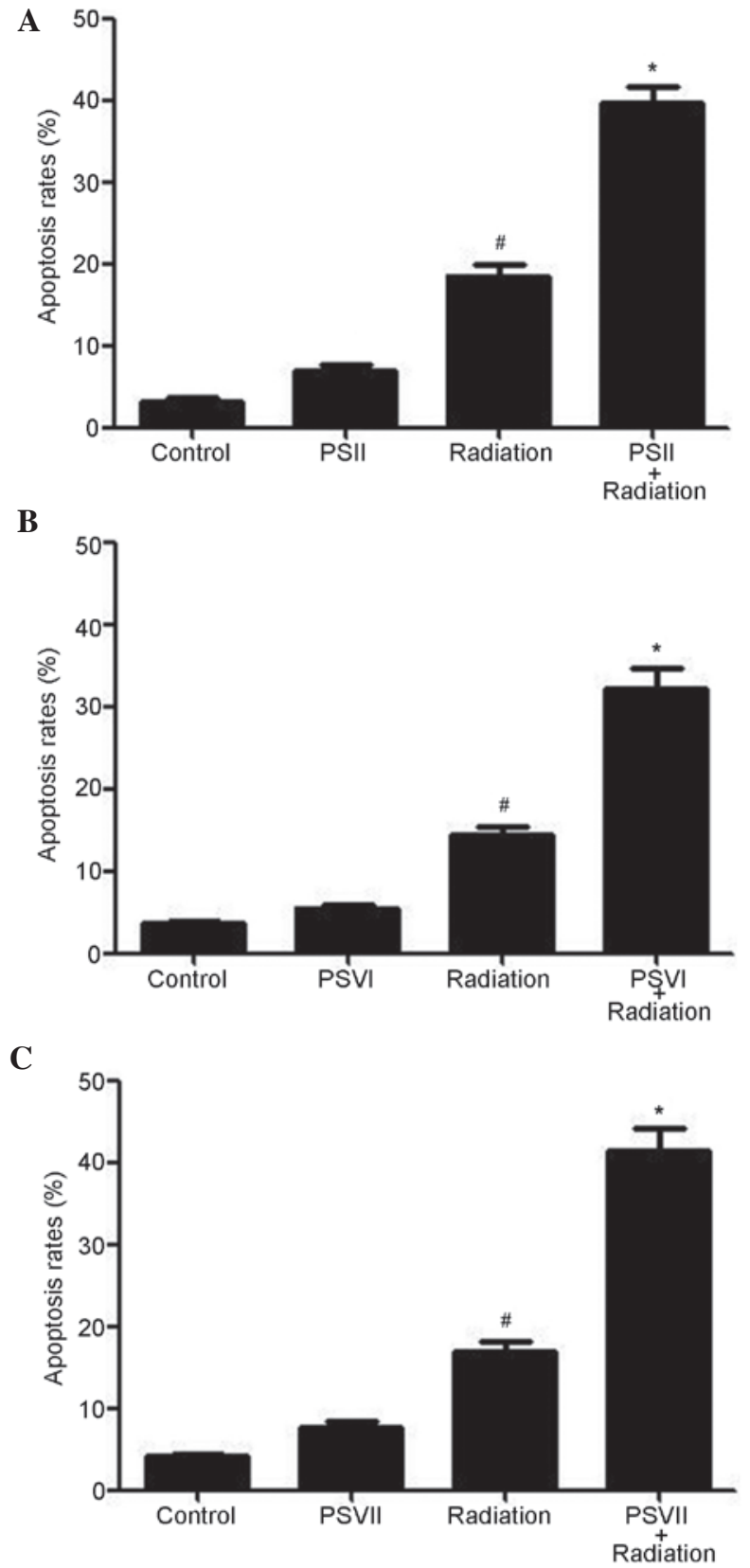

Figure 2. Flow cytometric analysis of cell apoptosis induced by (A) PSII, (B) PSVI and (C) PSVII $(0.5 \mu \mathrm{g} / \mathrm{ml}$ each). Data are presented as the mean \pm standard deviation. ${ }^{*} \mathrm{P}<0.01$ vs. the radiation group; ${ }^{\#} \mathrm{P}<0.05$ vs. the control group. PS, Paris Saponins.

gefitinib-resistant lung adenocarcinoma cells, PC-9-ZD cells were exposed to radiation (4 Gy) either with or without PSII, PSVI, and PSVII $(0.5 \mu \mathrm{g} / \mathrm{ml}$ each), and cell survival was determined using a colony formation assay. As shown in Fig. $1 \mathrm{~A}-\mathrm{C}$, the cell survival rates were significantly reduced in the combined treatment groups, as compared with the radiation only group $\left({ }^{*} \mathrm{P}<0.01\right)$. These results suggest that PC-9-ZD cells are more sensitive to the combination treatment than to either treatment alone.

PSII, PSVI and PSVII induce apoptosis of irradiated PC-9-ZD cells. Annexin V/PI double staining was used to evaluate the apoptosis induced by PSII, PSVI, and PSVII $(0.5 \mu \mathrm{g} / \mathrm{ml}$ each $)$ in irradiated PC-9-ZD cells. As shown in Fig. 2A-C, irradiation 
A

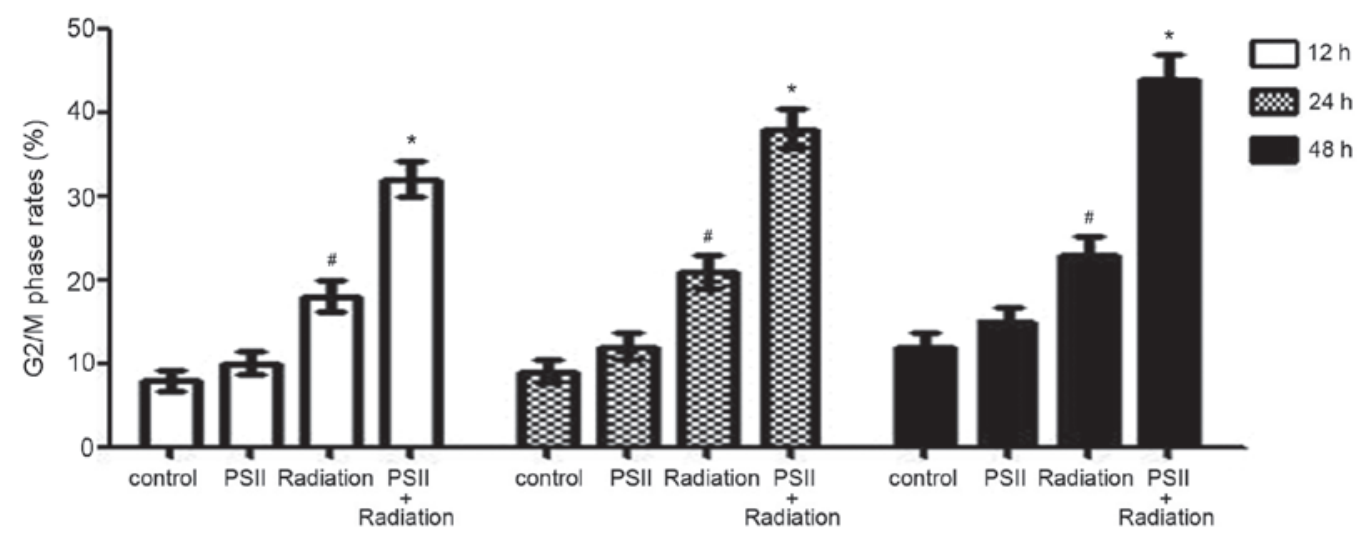

B

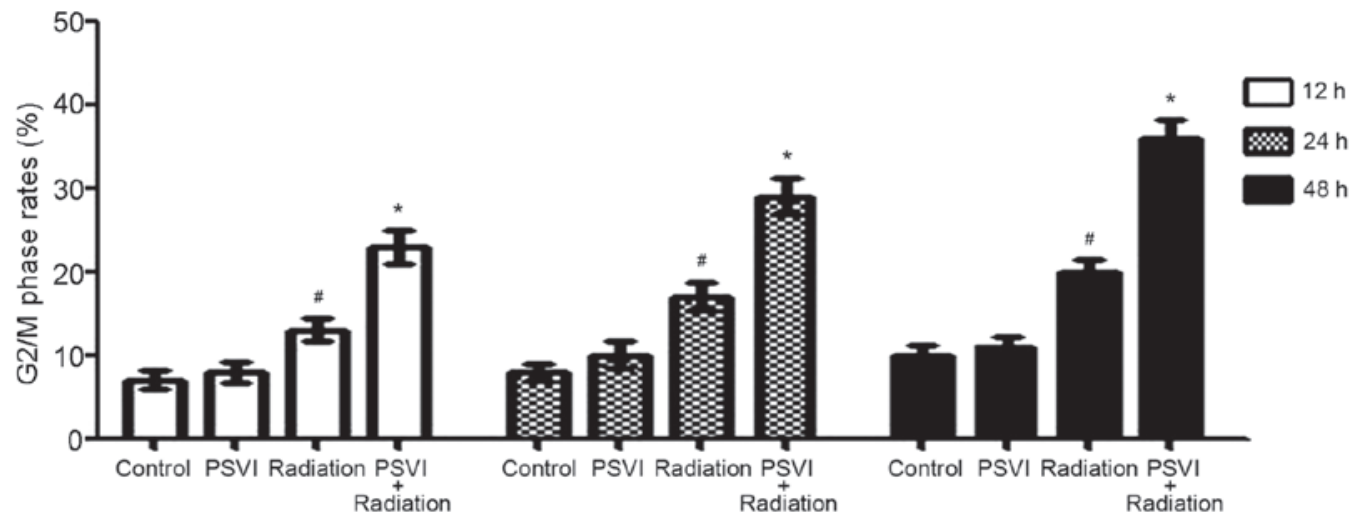

C

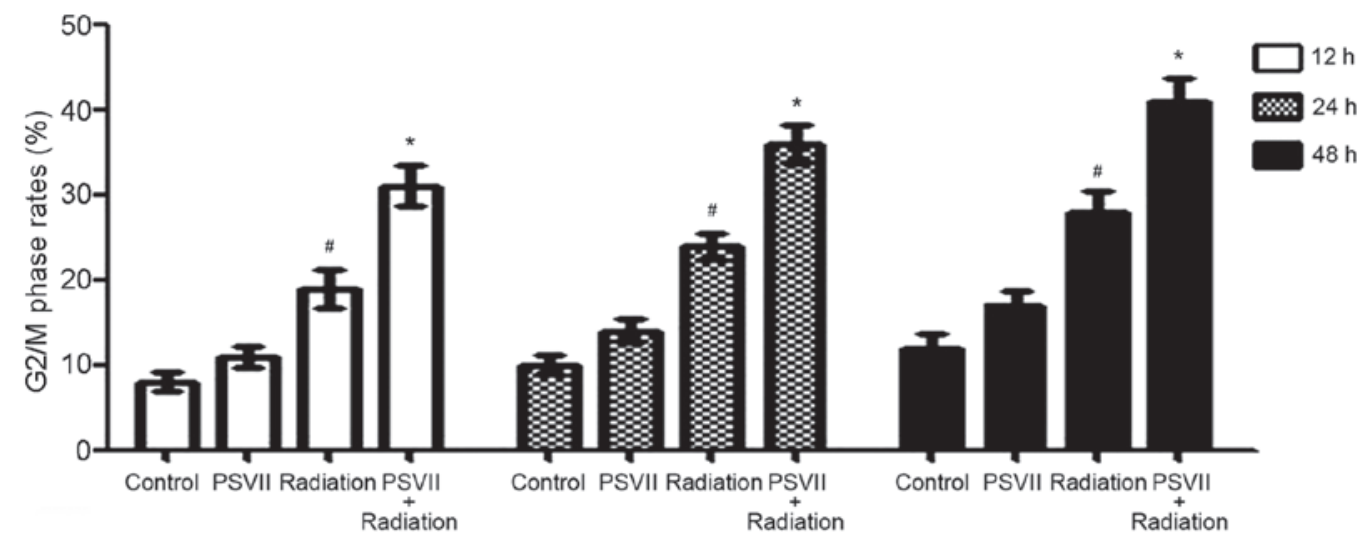

Figure 3. Flow cytometric analysis of cell cycle arrest in the $\mathrm{G}_{2} / \mathrm{M}$ phase induced by (A) PSII, (B) PSVI and (C) PSVII ( $0.5 \mu \mathrm{g} / \mathrm{ml}$ each). Data are presented as the mean \pm standard deviation. ${ }^{*} \mathrm{P}<0.01$ vs. the radiation only group; ${ }^{\#} \mathrm{P}<0.05$ vs. the control group. PS, Paris Saponins.

increased apoptosis levels at $24 \mathrm{~h}$; however, combined treatment with PS (II, VI or VII) further increased apoptosis levels $(\mathrm{P}<0.01)$. These results suggested that treatment with PSs significantly increases radiation-induced apoptosis.

PSII, PSVI, and PSVII induce $G_{2} / M$ arrest of irradiated $P C-9-Z D$ cells. In order to determine whether the radiosensitivity induced by PSs were due to cell cycle arrest, the effects of PSII, PSVI and PSVII $(0.5 \mu \mathrm{g} / \mathrm{ml}$ each $)$ on cell cycle distribution were observed. Irradiation alone induced $\mathrm{G}_{2} / \mathrm{M}$ phase arrest in a time-dependent manner, as compared with the control group $(\mathrm{P}<0.01)$. However, treatment with PSII, PSVI and PSVII following irradiation further changed the cycle distribution of irradiated cells, leading to a significant increase in cell cycle arrest at the $\mathrm{G}_{2} / \mathrm{M}$ phase in a time-dependent manner, as compared with the radiation group $(\mathrm{P}<0.01$; Fig. 3A-C).

PSII, PSVI, and PSVII upregulate p21/Waf1/Cip1, caspase-3, and Bax protein expression levels, and downregulate Bcl-2 protein expression levels in irradiated PC-9-ZD cells. The expression levels of $\mathrm{p} 21 / \mathrm{Waf} 1 / \mathrm{Cip} 1$, which are the most important regulators of the cell cycle checkpoint (37), and caspase-3, Bax and Bcl-2, which are important apoptosis regulators (38-41), were investigated to determine which molecules were involved in PS-induced cell cycle arrest and apoptosis in irradiated PC-9-ZD cells. PSII, PSVI, and PSVII $(0.5 \mu \mathrm{g} / \mathrm{ml})$ significantly increased the expression levels of p21/Waf1/Cip1, caspase-3 and Bax in irradiated cells, and significantly decreased the expression levels of Bcl-2 in 
A

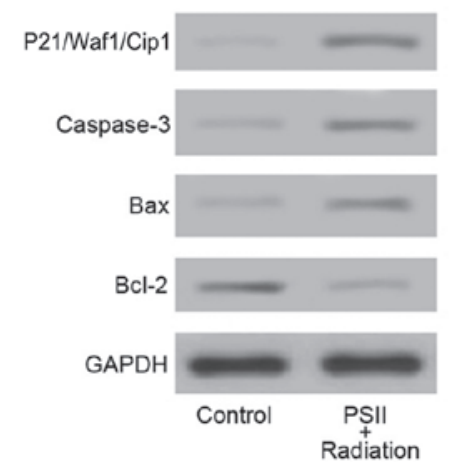

B

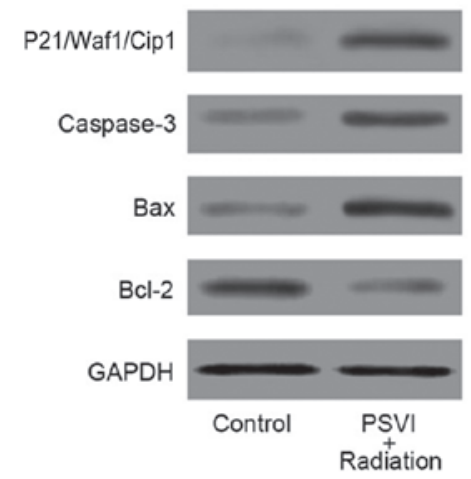

C

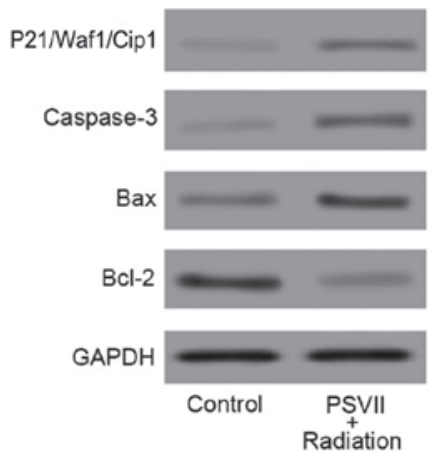

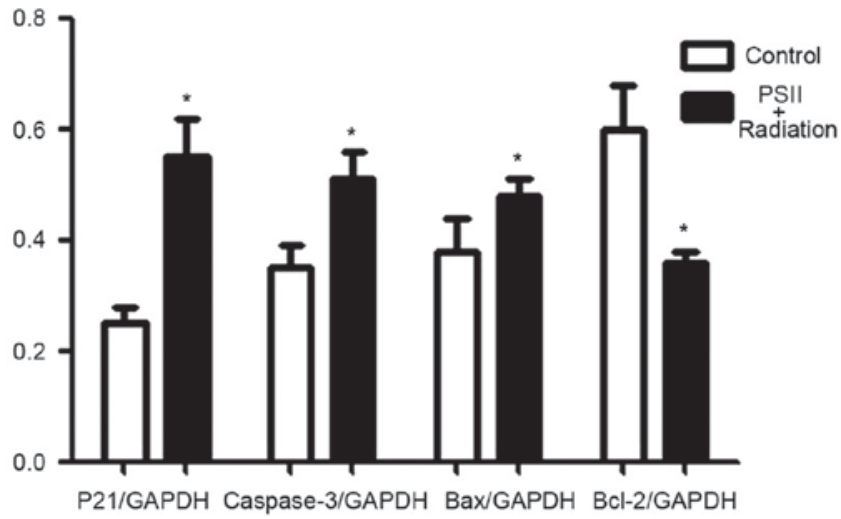
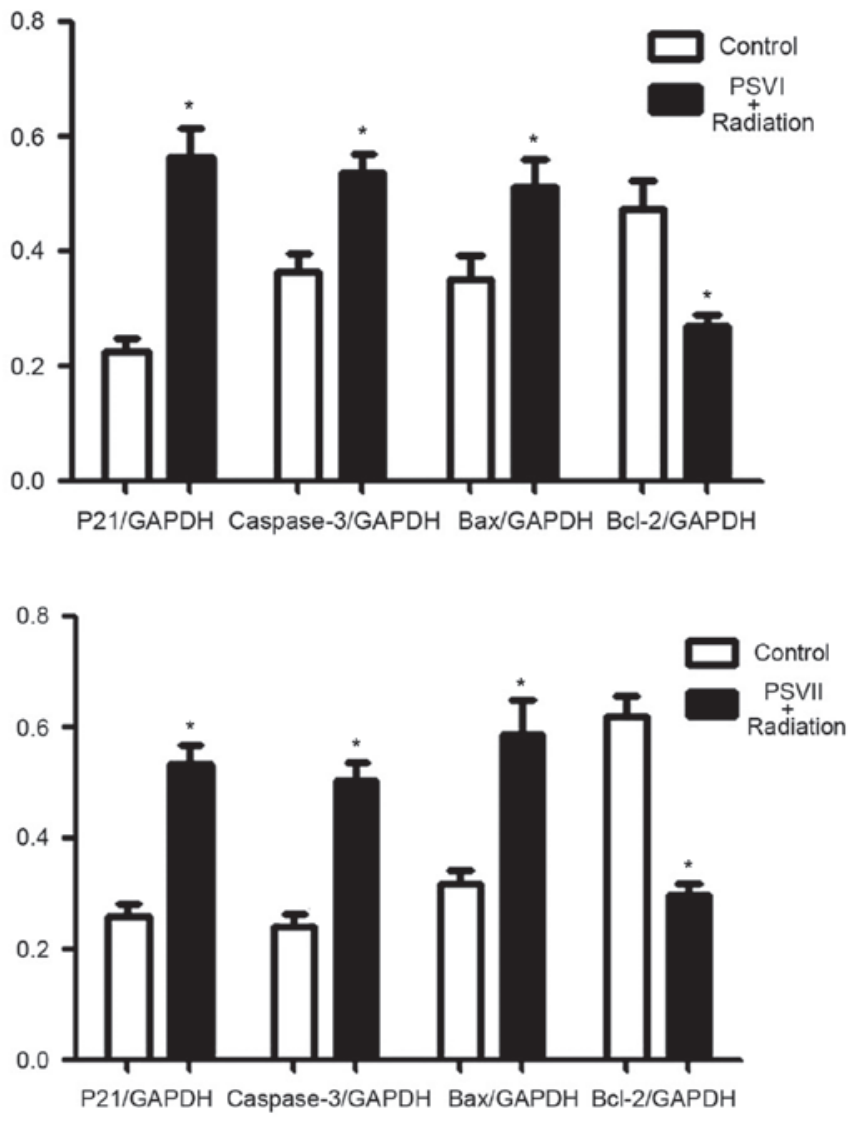

Figure 4. Western blot analysis of p21/Waf1/Cip1, caspase-3, Bax and Bcl-2 protein expression levels following treatment with (A) PSII, (B) PSVI or (C) PSVII $\left(0.5 \mu \mathrm{g} / \mathrm{ml}\right.$ each). Data are presented as the mean \pm standard deviation. ${ }^{*} \mathrm{P}<0.01$ vs. the control groups. PS, Paris Saponins; Bcl-2, B cell lymphoma 2 ; Bax, Bcl-2-associated X protein.

irradiated cells $(\mathrm{P}<0.01$; Fig. $4 \mathrm{~A}-\mathrm{C})$. These results suggest that increased $\mathrm{p} 21 / \mathrm{Waf} 1 / \mathrm{Cip} 1$ expression levels may contribute to $\mathrm{G}_{2} / \mathrm{M}$ phase arrest, and increased caspase- 3 and Bax expression levels, as well as decreased Bcl-2 expression levels, may contribute to PS-induced apoptosis in irradiated PC-9-ZD cells.

\section{Discussion}

Inhibition of EGFR has emerged as a promising cancer therapy approach for the treatment of EGFR-mutated lung cancer over the last decade (5). Previous studies have reported that the majority of patients who initially responded to EGFR inhibition, eventually exhibited tumor recurrence (6-8). These results suggested the existence of mechanisms underlying acquired resistance to EGFR inhibitors. These include mutations in EGFR or V-Ki-ras2 Kirsten rat sarcoma viral oncogene homolog, or the activation of other receptor tyrosine kinases, such as ErbB3 or c-Met (42). A comparative analysis revealed that acquired resistance to EGFR inhibitors was associated with cross-resistance to radiation (43). Therefore, radiation is less effective in EGFR-TKI-resistant lung cancer.

Previous findings have demonstrated that PSs are able to induce cell death, reverse multidrug resistance, and inhibit angiogenesis and tumor cell migration by modulating 
various signaling pathways (30-32,35). PSII suppresses the growth of human ovarian cancer xenografts by modulating VEGF-mediated angiogenesis (30) and tumor cell migration by elevating the expression levels of pro-apoptotic elements including Bax, cytosolic cytochrome $c$, activated caspase-3, and activated caspase- 9 , and by reducing extracellular signal-regulated kinase (ERK)1/2 phosphorylation and anti-apoptotic Bcl-2 expression levels (31). PSVII induces cell apoptosis and cell cycle arrest in the $\mathrm{G}_{1}$ phase, and triggers apoptosis in a caspase-3-dependent manner by downregulating mitogen-activated protein kinase kinase 1/2 expression, ERK1/2 phosphorylation, and by suppressing the protein kinase B signaling pathway (32). PSVII reverses multidrug resistance in MCF-7/ADR adriamycin-resistant cells via P-glycoprotein inhibition and apoptosis augmentation (35). In our previous study, the results demonstrated that PSI was able to enhance the radiosensitivity of gefitinib-resistant PC-9-ZD lung adenocarcinoma cells, which was associated with cell cycle arrest at the $G_{2} / M$ phase and apoptosis via increased caspase-3, Bax and p21/Waf1/Cip1 expression levels, and decreased Bcl-2 expression levels (13). PSI, PSII, PSVI, and PSVII exhibit chemical structural similarities; however, to the best of our knowledge, no studies have yet to explore the efficacy and mechanisms underlying the radiosensitivity of PSs in EGFR-TKI resistance cells.

In the present study, the mechanism underlying the radiosensitivity induced by PSII, PSVI, and PSVII in EGFR-TKI-resistant cells was examined in order to develop PSII, PSVI, and PSVII radiosensitization agents for the treatment of EGFR-TKI-resistant lung cancer. The results demonstrated that PSII, PSVI, and PSVII significantly increased radiosensitivity in PC-9-ZD cells. These data provided reasonable evidence that addition of PS treatment to radiation may improve patient response to radiotherapy in EGFR-TKI-resistant lung cancer. It is widely-accepted that cellular response to radiation depends on the phase of the cell cycle the cells were in at the time of irradiation (44). Cells in the $G_{2} / M$ phase are the most sensitive to irradiation (45). In the present study, arrest in the $\mathrm{G}_{2} / \mathrm{M}$ phase was achieved by treatment with PSII, PSVI, and PSVII. The results demonstrated that PSII, PSVI, and PSVII induced marked changes in cell cycle distribution, leading to cell cycle arrest in the $\mathrm{G}_{2} / \mathrm{M}$ phase in a time-dependent manner. p21/Waf1/Cip1 is considered to be the most important cell cycle checkpoint regulator (37). The results obtained from the present study showed that treatment with PSII, PSVI, and PSVII significantly increased the expression levels of $\mathrm{p} 21 / \mathrm{Waf} 1 / \mathrm{Cip} 1$, which resulted in cell cycle progression through $\mathrm{G}_{2} / \mathrm{M}$ phase arrest in the PC-9-ZD cells. This suggested that $\mathrm{p} 21 / \mathrm{Waf} 1 / \mathrm{Cip} 1$ has an important role in mediating cell growth through $\mathrm{G}_{2} / \mathrm{M}$ phase arrest in gefitinib-resistant cell lines.

Furthermore, investigations analyzing apoptosis by fluorescence-activated cell sorting demonstrated significantly increased cell apoptosis levels following treatment with PSII, PSVI, and PSVII. In the present study, apoptosis was the primary pathway to cell death induced by PSII, PSVI, and PSVII in the irradiated cells. The results also demonstrated that PSII, PSVI, and PSVII significantly increased apoptosis levels, as compared with radiation alone in PC-9-ZD cells. Caspases are important mediators of apoptosis (38). Among them, caspase- 3 is a frequently activated death protease, catalyzing the specific cleavage of numerous cellular proteins $(39,40)$. The Bcl-2 family, which comprises anti-apoptotic (including Bcl-2 and Bcl-extra large) and pro-apoptotic members (including Bax and Bcl-2-antagonist/killer 1), is the predominant regulator and mediator of cell apoptosis (41). To investigate the roles of PSII, PSVI, and PSVII in radiation-induced apoptosis in gefitinib-resistant PC-9-ZD cells, the expression levels of Bcl-2 family proteins and caspase-3 were analyzed in the present study. The results indicated that $\mathrm{Bcl}-2$ expression levels were decreased, and those of Bax and caspase-3 were increased following treatment with PSII, PSVI, and PSVII. Therefore, PSII, PSVI, and PSVII promoted radiation-induced apoptosis via Bcl-2, Bax, and caspase-3, eventually leading to enhanced radiosensitivity.

In conclusion, the results of the present study demonstrated that PSII, PSVI, and PSVII induced radiosensitivity in gefitinib-resistant cells by arresting cells in the $\mathrm{G}_{2} / \mathrm{M}$ phase and by enhancing the apoptosis response via the modulation of caspase-3, Bax, Bcl-2 and p21/Waf1/Cip1 expression levels, proteins which are involved in apoptosis and cell cycle signaling pathways. Therefore, PSII, PSVI, and PSVII may serve as radiosensitizers in gefitinib-resistant lung cancer. However, studies are required for further clinical evaluation.

\section{Acknowledgements}

The present study was supported by grants from the National Natural Science Foundation of China (grant nos. 81303274 and 81202947) and the Huzhou Science Project (grant no. 2015GY39).

\section{References}

1. Siegel RL, Miller KD and Jemal A: Cancer statistics, 2015. CA Cancer J Clin 65: 5-29, 2015.

2. Sordella R, Bell DW, Haber DA and Settleman J: Gefitinib-sensitizing EGFR mutations in lung cancer activate anti-apoptotic pathways. Science 305: 1163-1167, 2004.

3. Workman P: Altered states: Selectively drugging the Hsp90 cancer chaperone. Trends Mol Med 10: 47-51, 2004.

4. Kobayashi N, Toyooka S, Soh J, Yamamoto H, Dote H, Kawasaki K, Otani H, Kubo T, Jida M, Ueno T, et al: The anti-proliferative effect of heat shock protein 90 inhibitor, 17-DMAG, on non-small-cell lung cancers being resistant to EGFR tyrosine kinase inhibitor. Lung cancer 75: 161-166, 2012.

5. Langer CJ: Epidermal growth factor receptor inhibition in mutation-positive non-small-cell lung cancer: Is afatinib better or simply newer? J Clin Oncol 31: 3303-3306, 2013.

6. Arcila ME, Nafa K, Chaft JE, Rekhtman N, Lau C, Reva BA, Zakowski MF, Kris MG and Ladanyi M: EGFR exon 20 insertion mutations in lung adenocarcinomas: Prevalence, molecular heterogeneity, and clinicopathologic characteristics. Mol Cancer Ther 12: 220-229, 2013.

7. Pao W, Miller VA, Politi KA, Riely GJ, Somwar R, Zakowski MF, Kris MG and Varmus H: Acquired resistance of lung adenocarcinomas to gefitinib or erlotinib is associated with a second mutation in the EGFR kinase domain. PLoS Med 2: e73, 2005.

8. Gainor JF and Shaw AT: Emerging paradigms in the development of resistance to tyrosine kinase inhibitors in lung cancer. J Clin Oncol 31: 3987-3996, 2013.

9. Yu HA, Arcila ME, Rekhtman N, Sima CS, Zakowski MF, Pao W, Kris MG, Miller VA, Ladanyi M and Riely GJ: Analysis of tumor specimens at the time of acquired resistance to EGFR-TKI therapy in 155 patients with EGFR-mutant lung cancers. Clin Cancer Res 19: 2240-2247, 2013.

10. Lutz ST, Jones J and Chow E: Role of radiation therapy in palliative care of the patient with cancer. J Clin Oncol 32: 2913-2919, 2014. 
11. Socinski MA, Rosenman JG, Halle J, Schell MJ, Lin Y, Russo S, Rivera MP, Clark J, Limentani S, Fraser R, et al: Dose-escalating conformal thoracic radiation therapy with induction and concurrent carboplatin/paclitaxel in unresectable stage IIA/B nonsmall cell lung carcinoma: A modified phase I/II trial. Cancer 92: 1213-1223, 2001.

12. Santana-Davila R, Devisetty K, Szabo A, Sparapani R, Arce-Lara C, Gore EM, Moran A, Williams CD, Kelley MJ and Whittle J: Cisplatin and etoposide versus carboplatin and paclitaxel with concurrent radiotherapy for stage III non-small-cell lung cancer: an analysis of Veterans Health Administration data. J Clin Oncol 33: 567-574, 2015.

13. Jiang H, Zhao P, Feng J, Su D and Ma S: Effect of Paris saponin I on radiosensitivity in a gefitinib-resistant lung adenocarcinoma cell line. Oncol Lett 7: 2059-2064, 2014.

14. Yan L, Gao W, Zhang Y and Wang Y: A new phenylpropanoid glycosides from Paris polyphylla var. yunnanensis. Fitoterapia 79: 306-307, 2008

15. Negi JS, Bisht VK, Bhandari AK, Bhatt VP, Singh P and Singh N: Paris polyphylla: Chemical and biological prospectives. Anticancer Agents Med Chem 14: 833-839, 2014.

16. He H, Zheng L, Sun YP, Zhang GW and Yue ZG: Steroidal saponins from Paris polyphylla suppress adhesion, migration and invasion of human lung cancer A549 cells via down-regulating MMP-2 and MMP-9. Asian Pac J Cancer Prev 15: 10911-10916, 2014.

17. Cheng ZX, Liu BR, Qian XP, Ding YT, Hu WJ, Sun J and Yu LX: Proteomic analysis of anti-tumor effects by Rhizoma Paridis total saponin treatment in HepG2 cells J Ethnopharmacol 120: 129-137, 2008.

18. Man S, Gao W, Zhang Y, Yan L, Ma C, Liu C and Huang L: Anti-tumor and antimetastatic activities of Rhizoma Paridis saponins. Steroids 74: 1051-1056, 2009.

19. Ma DD, Lu HX, Xu LS and Xiao W: Polyphyllin D exerts potent anti-tumour effects on Lewis cancer cells under hypoxic conditions. J Int Med Res 37: 631-640, 2009.

20. Shuli M, Wenyuan G, Yanjun Z, Chaoyi M, Liu Y and Yiwen L: Paridis saponins inhibiting carcinoma growth and metastasis in vitro and in vivo. Arch Pharm Res 34: 43-50, 2011.

21. GuangLie C, WeiShi G, GaiLing H and JianPing C: Effect of Paris saponin on antitumor and immune function in U14 tumor-bearing mice. Afr J Tradit Complement Altern Med 10: 503-507, 2013.

22. Wen F, Yin H, Chen C, Liu X, Xue D, Chen T, He J and Zhang H: Chemical characteristics of saponins from Paris fargesi var. brevipetala and cytotoxic activity of its main ingredient, Paris saponin H. Fitoterapia 83: 627-635, 2012.

23. Zhao Y, Kang LP, Liu YX, Liang YG, Tan DW, Yu ZY, Cong YW and Ma BP: Steroidal saponins from the rhizome of Paris polyphylla and their cytotoxic activities. Planta Med 75: 356-363, 2009.

24. Yan LL, Zhang YJ, Gao WY, Man SL and Wang Y: In vitro and in vivo anticancer activity of steroid saponins of Paris polyphylla var. yunnanensis. Exp Oncol 31: 27-32, 2009.

25. He H, Sun YP, Zheng L and Yue ZG: Steroidal saponins from Paris polyphylla induce apoptotic cell death and autophagy in A549 human lung cancer cells. Asian Pac J Cancer Prev 16: 1169-1173, 2015

26. Jiang H, Zhao PJ, Su D, Feng J and Ma SL: Paris saponin induces apoptosis via increasing the $\mathrm{Bax} / \mathrm{Bcl}-2$ ratio and caspase-3 expression in gefitinib-resistant non-small cell lung cancer in vitro and in vivo. Mol Med Rep 9: 2265-2272, 2014.

27. Xiao X, Bai P, Bui Nguyen TM, Xiao J, Liu S, Yang G, $\mathrm{Hu}$ L, Chen X, Zhang X, Liu J and Wang H: The antitumoral effect of Paris Saponin I associated with the induction of apoptosis through the mitochondrial pathway. Mol Cancer Ther 8: 1179-1188, 2009.
28. Xiao M, Dai X,He X,Zhou R, Zhang B,Hu G,Huang Z and Fan X: Paris saponin I induces $\mathrm{G}_{2} / \mathrm{M}$ cell cycle arrest and apoptosis in human gastric carcinoma SGC7901 cells. J Huazhong Univ Sci Technolog Med Sci 31: 768-772, 2011.

29. Zhao P, Jiang H, Su D, Feng J, Ma S and Zhu X: Inhibition of cell proliferation by mild hyperthermia at $43^{\circ} \mathrm{C}$ with Paris Saponin I in the lung adenocarcinoma cell line PC-9. Mol Med Rep 11: 327-332, 2015.

30. Xiao X, Yang M, Xiao J, Zou J, Huang Q, Yang K, Zhang B, Yang F, Liu S, Wang H and Bai P: Paris Saponin II suppresses the growth of human ovarian cancer xenografts via modulating VEGF-mediated angiogenesis and tumor cell migration. Cancer Chemother Pharmacol 73: 807-818, 2014.

31. Xiao X, Zou J, Bui-Nguyen TM, Bai P, Gao L, Liu J, Liu S, Xiao J, Chen X, Zhang X and Wang H: Paris saponin II of Rhizoma Paridis - a novel inducer of apoptosis in human ovarian cancer cells. Biosci Trends 6: 201-211, 2012.

32. Li Y, Sun Y, Fan L, Zhang F, Meng J, Han J, Guo X, Zhang D, Zhang R, Yue Z and Mei Q: Paris saponin VII inhibits growth of colorectal cancer cells through Ras signaling pathway. Biochem Pharmacol 88: 150-157, 2014

33. Zhang W, Zhang D, Ma X, Liu Z, Li F and Wu D: Paris saponin VII suppressed the growth of human cervical cancer Hela cells. Eur J Med Res 19: 41, 2014

34. Fan L, Li Y, Sun Y, Yue Z, Meng J, Zhang X, Zhang R, Zhang D, Zhang $\mathrm{F}$ and Mei Q: Paris saponin VII inhibits metastasis by modulating matrix metalloproteinases in colorectal cancer cells. Mol Med Rep 11: 705-711, 2015.

35. Li Y, Fan L, Sun Y, Miao X, Zhang F, Meng J, Han J, Zhang D, Zhang R, Yue Z and Mei Q: Paris saponin VII from trillium tschonoskii reverses multidrug resistance of adriamycin-resistant MCF-7/ADR cells via P-glycoprotein inhibition and apoptosis augmentation. J Ethnopharmacol 154: 728-734, 2014.

36. Ji Y, Ma SL, Zhang YP, Tang JJ, Wu YM and Lu YJ: Combined treatment with TNF- $\alpha /$ gefitinib alleviates the resistance to gefitinib in PC-9 cells. Anticancer Drugs 20: 832-837, 2009.

37. Deckbar D, Jeggo PA and Löbrich M: Understanding the limitations of radiation-induced cell cycle checkpoints. Crit Rev Biochem Mol Biol 46: 271-283, 2011.

38. McIlwain DR, Berger T and Mak TW: Caspase functions in cell death and disease. Cold Spring Harb Perspect Biol 5: a008656, 2013.

39. Hu Q, Peng J, Liu W, He X, Cui L, Chen X, Yang M, Liu H, Liu $\mathrm{S}$ and Wang $\mathrm{H}$ : Elevated cleaved caspase-3 is associated with shortened overall survival in several cancer types. Int J Clin Exp Pathol 7: 5057-5070, 2014.

40. Dhar R, Persaud SD, Mireles JR and Basu A: Proteolytic cleavage of p70 ribosomal S6 kinase by caspase-3 during DNA damage-induced apoptosis. Biochemistry 48: 1474-1480, 2009.

41. Shroff EH, Snyder C and Chandel NS: Bcl-2 family members regulate anoxia-induced cell death. Antioxid Redox Signal 9: 1405-1409, 2007.

42. Engelman JA and Jänne PA: Mechanisms of acquired resistance to epidermal growth factor receptor tyrosine kinase inhibitors in non-small cell Lung cancer. Clin Cancer Res 14: 2895-2899, 2008.

43. Huang S, Benavente S, Armstrong EA, Li C, Wheeler DL and Harari PM: p53 modulates acquired resistance to EGFR inhibitors and radiation. Cancer Res 71: 7071-7079, 2011.

44. Begg AC, Stewart FA and Vens C: Strategies to improve radiotherapy with targeted drugs. Nat Rev Cancer 11: 239-253, 2011.

45. Chetty C, Bhoopathi P, Rao JS and Lakka SS: Inhibition of matrix metalloproteinase- 2 enhances radiosensitivity by abrogating radiation-induced FoxM1-mediated G2/M arrest in A549 lung cancer cells. Int J Cancer 124: 2468-2477, 2009. 